\title{
"I felt very small and embarrassed by the health care provider when I requested to be tested for syphilis": barriers and facilitators of regular syphilis and HIV testing among female sex workers in Uganda
}

\author{
Richard Muhindo ${ }^{1 *}$, Andrew Mujugira ${ }^{2,3}$, Barbara Castelnuovo², Nelson K. Sewankambo ${ }^{4}$,
} Rosalind Parkes-Ratanshi ${ }^{2,5}$, Nazarius Mbona Tumwesigye ${ }^{3}$, Edith Nakku-Joloba ${ }^{3}$ and Juliet Kiguli ${ }^{3}$

\begin{abstract}
Background: Periodic testing of female sex workers (FSW) for sexually transmitted infections (STIS) is a core component of global and national responses to achieve population-level STI elimination. We conducted a qualitative study to explore barriers and facilitators of regular syphilis and HIV testing among FSW in Uganda.
\end{abstract}

Methods: Within a quasi-experimental study among 436 FSW to assess the effect of peer education and text message reminders on uptake of regular STI and HIV testing among FSW, we conducted 48 qualitative interviews in four cities in Uganda from August-December 2018. We purposively selected FSW who tested for syphilis and HIV every 3-6 months; 12 FSW were interviewed in each city. Sex worker interviews explored: 1) reasons for periodic syphilis and HIV testing; 2) barriers and facilitators of testing; 3) experiences of testing; and 4) challenges faced while seeking testing services. Data were analyzed using thematic content analysis.

Results: Thematic analysis revealed individual- and health system-level barriers and facilitators of testing. For syphilis, barriers were a) interpersonal stigma, low perceived severity of syphilis and testing misconceptions (individual); and b) judgmental provider attitudes, paucity of facilities offering syphilis testing, stockouts of test kits and high cost (health system). Facilitators were c) desire to remain healthy, get married and have children, knowing the benefits of early treatment, influence of male partners/clients and normative testing behaviors (individual); and d) sex worker clinics offering dual syphilis/HIV testing (health system). For HIV, barriers included: a) internalized stigma (individual); and b) unfavorable clinic hours, stigma, discrimination, and unfriendly provider (health system). Facilitators were a) motivations to stay healthy and attract clients, habitual testing, self-efficacy, doubts about accuracy of negative test results, and use of post-exposure prophylaxis (individual); and d) availability of testing

\footnotetext{
* Correspondence: r.muhindo@yahoo.com

'Department of Nursing, College of Health Sciences, Makerere University, Kampala, Uganda

Full list of author information is available at the end of the article
}

(c) The Author(s). 2021 Open Access This article is licensed under a Creative Commons Attribution 4.0 International License, which permits use, sharing, adaptation, distribution and reproduction in any medium or format, as long as you give appropriate credit to the original author(s) and the source, provide a link to the Creative Commons licence, and indicate if changes were made. The images or other third party material in this article are included in the article's Creative Commons licence, unless indicated otherwise in a credit line to the material. If material is not included in the article's Creative Commons licence and your intended use is not permitted by statutory regulation or exceeds the permitted use, you will need to obtain permission directly from the copyright holder. To view a copy of this licence, visit http://creativecommons.org/licenses/by/4.0/. The Creative Commons Public Domain Dedication waiver (http://creativecommons.org/publicdomain/zero/1.0/) applies to the data made available in this article, unless otherwise stated in a credit line to the data. 
facilities (health system). Syphilis and HIV had similar testing barriers and facilitators.

Conclusions: HIV programs are likely to be important entry points for syphilis testing among FSW. Multi-level interventions to address testing barriers should consider focusing on these service delivery points. Extending the dual syphilis and HIV testing approach to FSW may improve testing uptake for both infections at public health facilities and decrease population-level incidence.

Keywords: HIV, Syphilis, Dual testing, Female sex workers, Africa

\section{Introduction}

Periodic testing of female sex workers (FSW) for syphilis and HIV is a pivotal component of global and national responses to achieve elimination of the two diseases at population level [1-3]. Globally, FSW have a 30-times greater risk of HIV acquisition than the general population, and face a disproportionate STI burden [4]. Increasing uptake of HIV and syphilis testing services among FSW features prominently in the global strategy to end the AIDS epidemic by 2030 and the STI epidemic by 2040 [5-8]. The World Health Organization (WHO) recommends that FSW test for syphilis every 3-6 months, and for HIV every 6-12 months $[9,10]$. In Uganda, HIV testing services, including targeted moonlight outreach testing campaigns, are widely available at stand-alone voluntary counseling and testing clinics, health centers, hospitals and community outreaches [11-13]. However, despite the high burden of HIV 32$52 \%$ [14] and STIs [15] among FSW, regular dual testing for syphilis and HIV is still suboptimal. In 2019, only $14 \%$ of the FSW in the four Ugandan cities of Arua, Mbale, Mbarara and Kampala reported testing at least twice for syphilis in the prior 12 months compared with $67 \%$ for HIV [16].

Studies have shown that uptake of HIV and other STI testing among FSW is often limited by an interplay of factors operating at individual, societal, structural and policy levels [17, 18]. Factors including poor attitude, low risk perception, fear of positive test results, and low self-efficacy have been reported to limit uptake of HIV and STI testing services at individual level [11, 16-18]. Various studies conducted in India, Zambia, South Africa, Mozambique, and Kenya show that stigma is still a pervasive testing barrier at individual, inter-personal, and societal levels [19-22]. At structural level, long waiting times, lack of privacy and confidentiality, poor physical state of health facilities, discrimination, lack of medicine and test supplies, and uncaring provider attitudes are barriers to testing uptake [11, 18]. Inconvenient clinic hours are a barrier at organizational and policy level [18]. In Uganda, a recent qualitative study found that limited awareness of prevention services, fears, misconceptions, stigma, and inconvenient hours of operation of the clinics were barriers to HIV testing among
FSW [11]. Barriers and facilitators of testing may vary for different STIs. However, most of the studies that explore barriers and facilitators of testing in Uganda, and elsewhere on the continent, only focus on HIV.

Scaling up point-of-care (POC) testing for HIV and syphilis increases uptake of testing services by FSW [23] and enables early treatment of both diseases [24, 25]. Routine HIV testing in antenatal care increases testing uptake by FSW [19]. Thus, dual syphilis and HIV testing at HIV clinics could facilitate syphilis screening among FSW and contribute to the WHO global strategy of ending the STI epidemic by 2040 [5, 6]. In this study we explored barriers and facilitators to regular testing for syphilis and HIV among FSW in Uganda.

\section{Methods}

\section{Study design and setting}

This explorative qualitative study was nested in a quasiexperimental study that assessed the effect of peer education and text message reminders on uptake of regular STI and HIV testing among sex workers in Uganda, as previously described [26]. Between August and December 2018, we conducted 48 in-depth interviews with FSW in the four cities of Arua, Kampala, Mbale, and Mbarara (combined population 1,857,088) located in the Northern, Central, Eastern and Western regions of Uganda, respectively [27]. High concentrations of sex work and HIV prevalence have been reported in major cities and towns in Uganda [28, 29].

\section{Sampling and recruitment}

Study eligibility included females aged $\geq 18$ years, selfreport of selling sex for goods or money in the prior 12 months, receipt of regular syphilis and HIV testing every 3-6 months, not on antiretroviral treatment (ART) or living with HIV. Potential participants were purposely identified $[30,31]$ following participation in a questionnaire-based survey to describe regular syphilis and HIV screening practices [16]. Prior to participant recruitment, a mapping exercise was conducted to gain an understanding of time of sex work, sex work hotspots, typologies, sex work procurer connections and territorial management in each of the city, as previously described $[16,26]$. Lists of eligible participants describing their 
demographic characteristics and telephone contacts were drawn for each city. A convenience sample of $12 \mathrm{FSW}$ was interviewed per city. The participants were purposely selected to include FSW from different age and educational strata of 18-24 years, 25-29 years, and $\geq 30$ years, and none, primary, secondary, or tertiary, respectively. Prior contact was made with the participants via telephone calls. Participants who declined to participate were replaced with eligible participants on the list within the same city and strata. A total of 48 interviews were conducted.

\section{Data collection}

We conducted a single, in person in-depth interview with each participant. We used an interview guide to explore FSW experiences of regular syphilis and HIV testing, their personal motivations, challenges, and facilitators. Interview guide topics included reasons for periodic syphilis and HIV testing, barriers and facilitators of testing, general testing experiences and challenges faced while seeking testing services. For clarity of interview questions, the guide was piloted with four FSW in a municipality outside the study sites prior to use. Individual interviews were conducted in a language of the participant's preference (English, Luganda or Runyankore) at venue of their choice where conversations could not be overheard. All interviews were conducted and audio recorded by the principal investigator $(\mathrm{RM})$, after he completed an online research ethics course with emphasis on research with vulnerable populations. All participants provided written informed consent and were reimbursed for their time in accordance with local ethics guidance.

\section{Data management and analysis}

Data were analyzed using thematic analysis, which involves presenting experiences, meanings and realities of participants [32,33]. All audio recorded interviews were transcribed verbatim and translated into English. Next was the decontextualization or familiarization phase, in which author RM read through all the transcripts to obtain a general sense of information therein and achieve immersion [33, 34]. RM checked all transcripts for errors by simultaneously listening to the audio-recording and proofreading the transcripts. Following decontextualization, RM and two independent qualitative researchers (SI and WG, PhD trained social scientists not directly involved in data collection) separately prepared the initial codes covering the broader themes (barriers and facilitators) [34, 35]. Codes were compared and synchronized; a codebook was used to code the remaining the transcripts. Emerging codes were condensed into meaningful units [36-38] to generate independent lists of codes, categories, and subcategories. During the process, we constantly compared the data with codes. Codes and sub-categories were contrasted across cities and participant characteristics (age, education, and marital status). The sub-categories and categories were further reviewed by $\mathrm{MM}$, a $\mathrm{PhD}$ student with qualitative analysis expertise, and other co-investigators to ensure salient categories were captured and suitable quotes selected for inclusion. The Consolidated Criteria for Reporting Qualitative Studies checklist was used for reporting study findings [39].

\section{Ethical approval}

The study was approved by Makerere University School of Public Health Higher Degrees Research and Ethics Committee, and Uganda National Council for Science and Technology (HS 2403). All participants provided written informed consent in English or their local language. All interviews were conducted at places agreeable to participants where conservations could not be overheard.

\section{Results}

Forty-eight participants were interviewed across the four cities. The median age was 28 years (interquartile range [IQR], 22-29), and the median duration of sex work was 36 months (IQR 24-54) (Table 1). Fifty two percent had obtained secondary education ( $\geq 7$ years of education) and $31 \%$ had primary or no formal education. Half (52\%) had never married. FSW solicited clients through bars or clubs (36\%), on the street (31\%), lodges $(18 \%)$, and brothels (9\%). For two-thirds (63\%), sex work was the only source of income. All 48 participants reported testing for syphilis and HIV in the prior three months. Across the four cities, participants reported engaging in risky sexual practices and described their testing practices as habitual.

\section{Barriers and facilitators of regular syphilis and HIV testing} Participants described several individual and health system factors as barriers and facilitators of regular syphilis and HIV testing (Fig. 1). Key personal barriers included low perceived severity, misconceptions for syphilis or internalized stigma for both syphilis and HIV. Service delivery barriers included provider practices, stock-outs of syphilis testing kits, high cost of syphilis testing, stigma and discrimination, unfavorable clinic operating hours and uncaring attitudes of HIV providers. Dual testing was mainly facilitated by presence of specific-FSW or non-governmental organization (NGO) clinics that offered integrated STI/HIV testing services. At individual level, testing was mainly facilitated by fears and concerns (i.e., increased HIV risk acquisition, inability to bear 
Table 1 Characteristics of participants $(N=48)$

\begin{tabular}{ll}
\hline Variable & N (\%) or Median (IQR) \\
\hline Age (years) & $28(22-29)$ \\
Duration of sex work (months) & $36(24-54)$ \\
Biological children & $2(1-3)$ \\
Education level & \\
Primary or no formal education & $15(31.3)$ \\
Secondary & $25(52.0)$ \\
Higher education & $8(16.7)$ \\
Marital status & \\
Married & $3(6.3)$ \\
Separated & $13(27.1)$ \\
Widow & $7(14.6)$ \\
Never married & $25(52.0)$ \\
Solicitation of clients & \\
Street & $17(31.0)$ \\
Home & $3(5.5)$ \\
Lodge & $10(18.1)$ \\
Bar/Club & $20(36.4)$ \\
Brothel & $5(9.0)$ \\
Description of sex work & \\
Full time, no other source of income & $30(62.5)$ \\
Full time supplements income & $10(20.8)$ \\
Part-time, have other sources of income & $6(12.5)$ \\
Part-time, student & $2(4.2)$ \\
\hline
\end{tabular}

children, having syphilis would make one unable to satisfy clients or inability to attract clients, suddenly becoming sick, loss of work and inability to provide for significant others, and psychological anxiety (for HIV) at individual level. A coding tree of the barriers and facilitators of regular of syphilis and HIV testing among FSW is presented in Table 2.

\section{Low perceived severity, misconceptions, and internalized stigma}

Unlike HIV, syphilis was perceived a less serious health threat by most FSW. They reported that most FSW believed in testing for syphilis after developing the disease. To them this was a barrier to routine testing.

"Syphilis is not such a big issue like HIV. One can live with syphilis ... it is not easy to go and test when you have no signs. I test because when I go at our clinic in Mulago am told to test for syphilis" (30 year old FSW, Kampala).

Descriptions of internalized stigma as a barrier to both syphilis and HIV testing were amplified by fears of being seen at clinics or peers spreading rumours about one's perceived status. Rumour mongering was associated with loss of customers and income. These fears were more common among younger participants ( $\leq 24$ years).

"I sometimes fear finding people I know at the clinic .... I do not want them to know that I am doing this job. Also you are given a medical form if you test for syphilis ... your friends may get to know that you have syphilis and other diseases and tell other people which affects your business" (20 year old FSW, Mbale).

\section{Provider practices}

Syndromic STI management (i.e., treatment without testing), disrespectful and judgemental provider attitudes were reported to limit uptake of routine syphilis testing. Across the study sites, participants reported being prescribed antibiotics for STIs without testing even after requesting to be tested. It was observed that unlike HIV, healthcare workers (HCW) rarely emphasised syphilis testing in public health facilities unless one was pregnant.

HCWs never emphasize syphilis testing like they do for HIV .... I test for syphilis when I visit the MARPI clinic in Mengo because in other hospitals you are simply asked the signs and symptoms and thereafter they write for you medicines" (a 34 year old FSW, Kampala).

Among younger participants ( $\leq 24$ years), it was reported that unlike HIV, requesting a syphilis test was not easy. Such requests were associated with critical questioning from the providers. Participants reported being asked questions like, 'Who said you have syphilis'? 'What did you do'? 'What signs show you have syphilis'? or 'Are you a doctor in the consultation room'? These questions were perceived as embarrassing, disrespectful, and judgemental.

"I felt very small and embarrassed by the health care provider when I requested to be tested for syphilis. It is not easy to ask for a syphilis test. Two months ago I requested to be tested for syphilis at the hospital but the doctor looked at me and asked me who told me I had syphilis, what I had done, and which signs .... I felt very small, ashamed and insecure" (22 year old FSW, Mbarara).

In contrast, uncaring attitudes of $\mathrm{HCW}$ were reported to limit uptake of regular HIV testing. Most participants reported that HCW were unfriendly or uncaring especially at public facilities. $\mathrm{HCW}$ were perceived to be 


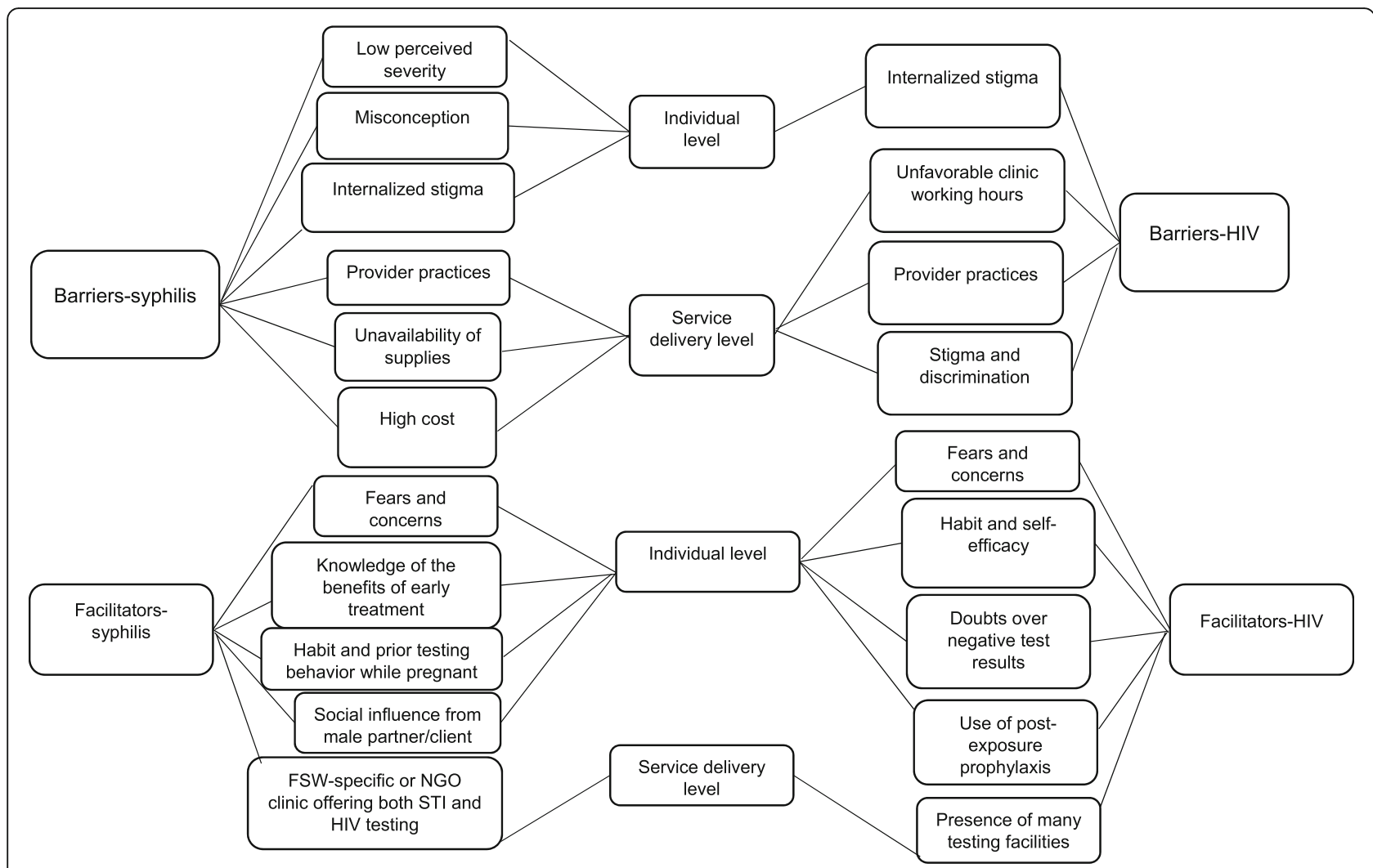

Fig. 1 Summary of subcategories and categories of the barriers and facilitators of regular syphilis and HIV testing

non-responsive and unfriendly to FSW, which led to long waiting times.

"I went to take an HIV test at government facility but the care was not good... doctors were too busy to attend to us that I spend the whole day in the hospital ... .now I test whenever I go to Kampala at a clinic in Mengo" (30 year old FSW, Mbarara).

\section{Unavailability of supplies and high cost}

Older participants ( $\geq 30$ years) cited being discouraged to seek syphilis screening due to frequent stock outs of testing kits and medicines. They observed that unlike HIV, testing kits for syphilis and antibiotics were seldom available at public health facilities.

"Unless you are pregnant, it is not easy to be tested for syphilis in public facilities because testing kits and medicines are not available" (32 year old FSW, Kampala).

STI testing was reported to be more expensive than HIV testing at private clinics. The low cost of HIV testing was attributed to the availability of several testing clinics.
"At least for HIV you can find many cheap testing places; testing for syphilis is very expensive in private clinics" (28 year old FSW in Mbale).

\section{Discrimination and stigma}

Experiences of discrimination were reported as to be a barrier to HIV testing by all participants. However, this mainly occurred at public health facilities unlike sex worker friendly clinics.

"I used to test for HIV from the main hospital but once $H C W$ realize you are a sex worker no one wants to attend to you or you will be the last to be seen. However, there are many testing canters in Arua .... I now test from Reproductive Health Uganda" (a 28 year old FSW, Arua).

\section{Unfavourable operating clinic hours}

Some participants reported unfavourable clinic working hours as a barrier to HIV testing. This was mainly in Kampala, the capital city.

"Like a week ago I went to a city council clinic not far from here. I reached there like at 3:00 pm to take an HIV test ... but I was told to 
Table 2 Coding tree of the potential barriers and facilitators of regular syphilis and HIV testing

\begin{tabular}{ll}
\hline Theme & Category \\
\hline Barriers & Low perceived severity \\
& Misconception \\
& Internalized stigma \\
& \\
& Provider practices \\
& \\
& \\
& \\
Hnfigma and discrimination \\
hours
\end{tabular}

Facilitators Fears and concerns

Inability to bear children due to syphilis and other STIS

Attracting and satisfying clients

Worry that syphilis and other STI increase HIV acquisition risk

Psychological fear of contracting HIV

Suddenly becoming sick and being unable to provide for significant others

Social influence

Knowledge of the benefits of early treatment

Habit and prior testing while pregnant
Influence of a regular male partner/boyfriend

Client demand for unprotected sex

Code Code

frequency

Syphilis is not like HIV, one can live with syphilis, hard to test for it unless sick, syphilis not a big issue, only fear HIV.

FSW think you can't just go and test for syphilis when you have no signs.

I fear finding people I know at the clinic as they could know 6 my work.

My friends may see the medical form and spread information if I am positive for syphilis and other STI.

\section{7}

Sometimes you ask for syphilis test, and they simply ask you the signs and write you medicine.

Doctors only encourage us to test for HIV.

I felt small and shamed, the health worker asked me what I was doing when I asked for a syphilis test, I was asked who told me I had syphilis and whether I was a doctor, I was embarrassed

The care is not good at government hospital, doctors are too busy to attend to us, I spend the whole day at the hospital just to take an HIV test

Unless you are pregnant it is not easy to be tested for syphilis at public hospitals, no syphilis testing kits

At least for HIV you can find many cheap testing services, but testing for syphilis is expensive in private clinics

We FSW when we visit public hospitals health workers just look at us, once they realize you are a sex worker no one wants to attend to you.

I test for all STIs because I want to get married, I want to bear children at some point, syphilis may affect your uterus and fail to bear children

In this job you have to be healthy and strong, syphilis and other STI reduces your capacity to satisfy clients, you lose clients.

Syphilis can make you easily get HIV.

Start imaging things until at test, I cannot settle until I test, test regularly to get psychological relief.

Suddenly becoming sick and stop working for my children, I 35 am in this job for my children I have to test every month or 3 months, I can't allow myself to become sick no one will look after my children.

Boyfriend insists on STI and HIV testing whenever we meet. 7

Whenever a client requests for unprotected sex.

Syphilis heals better if it has not spread widely in the body.

Now my habit to test every 3 months for HIV, during 40 pregnancy it was a must to test for syphilis and HIV I test for them together, I keep a diary to ensure I test every 3 months for HIV

It is easy to test every 3 months for HIV, developed courage to test every 3 months for HIV
32

6

(1)

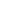

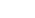

35

20

44


Table 2 Coding tree of the potential barriers and facilitators of regular syphilis and HIV testing (Continued)

\begin{tabular}{|c|c|c|c|}
\hline Theme & Sub-category & Code & $\begin{array}{l}\text { Code } \\
\text { frequency }\end{array}$ \\
\hline & $\begin{array}{l}\text { Doubts over negative test } \\
\text { results }\end{array}$ & $\begin{array}{l}\text { I have messed up a lot but am always told I am HIV } \\
\text { negative, I don't trust test results from outreaches, I doubt a } \\
\text { drop of blood from a finger can give true results }\end{array}$ & 10 \\
\hline & $\begin{array}{l}\text { Use of post-exposure } \\
\text { prophylaxis }\end{array}$ & $\begin{array}{l}\text { To get PEP after unprotected sex, after being forced into } \\
\text { live sex to obtain PEP }\end{array}$ & 5 \\
\hline & $\begin{array}{l}\text { Presence of specific or NGO } \\
\text { clinics offering both STI and } \\
\text { HIV testing }\end{array}$ & $\begin{array}{l}\text { I go to specific clinics for FSW that test HIV and other STIs, } \\
\text { at Reproductive health Uganda with small money you are } \\
\text { tested for HIV, syphilis, and Hepatitis }\end{array}$ & 32 \\
\hline & $\begin{array}{l}\text { Availability of many testing } \\
\text { facilities }\end{array}$ & $\begin{array}{l}\text { Easy to test for HIV because there are many testing clinics } \\
\text { unlike syphilis }\end{array}$ & 48 \\
\hline
\end{tabular}

come the following day because the clinic had closed ... I was very demoralized" (29 year old FSW, Kampala).

\section{Fears and concerns}

Regular testing for syphilis and HIV was mainly driven by fears and concerns about the impact of syphilis and HIV on one's own health, work, family responsibilities and future aspirations. Older participants ( $\geq 30$ years) reported fear of suddenly becoming sick, being unable to work and providing for one's children as a motivation for their regular testing behaviour. They expressed high risk perception for acquisition of HIV and other STIs, and believed one needed to remain physically attractive and strong to survive in sex work. They reported testing for both HIV and syphilis as they believed poor physical health was associated with failure to attract or satisfy customers. Regular testing meant accessing ART and STI treatment if one was found positive. Testing was also required before getting a post-exposure prophylaxis (PEP) prescription.

"I fear if I suddenly become sick and stop working ... I am in this job for my children. No one will take care of them if I allow myself to become sick. In this job you have to test for HIV and other diseases such that if found positive you immediately start medicine otherwise you will not be able to satisfy customers and continue working .... so for me, I test for HIV, syphilis, and hepatitis $B$ at RHU [Reproductive Health Uganda] every 6 months" (32 year old FSW, Arua).

Younger participants ( $\leq 24$ years) reported testing frequently for HIV to avoid anxiety. The fear of contracting HIV after condomless sex caused stress, experiences of anxiety, distress, and uneasiness. Condomless sex generates more earnings than sex with a condom and FSW sometimes face a dilemma between needing income and risking HIV infection from unprotected sex. Periodic testing was associated with emotional relief and happiness especially if one tested HIV-negative. The desire for psychological and emotional wellbeing motivated periodic testing for HIV. However, no psychological concerns were reported for syphilis.

"I sometimes try to insist on condom use but clients offer more money for unprotected sex ... and sometimes I have nothing to eat or feed my child ... so I test for HIV almost every month to feel relieved" (20 year old FSW, Mbale).

Similarly, dual syphilis and HIV testing was reported among participants with childbearing and marriage intentions. Syphilis was believed to cause infertility. The fear of being unable to bear children in the future promoted syphilis testing.

"In this job one can easily acquire infections that can affect their private parts (vagina) and even the uterus ... for me, at some point, I want to quit this job, get married and have children in future so I normally go to test for syphilis and HIV every two months" (23 year old FSW, Mbarara).

\section{Social influences}

Some participants reported testing for syphilis and HIV due to the influence of a distant partner or boyfriend who lived in a different part of the country. The partners were usually not aware of their participation in sex work. Their testing behaviour was motivated by request of the partner for fear of being infected.

"My boyfriend is not aware I do this job ... .we usually meet once every four months and normally he insists we must first test for HIV and syphilis" (23 year old FSW, Kampala).

Sometimes the demand for unprotected sex by male clients influenced frequent HIV testing behaviour. This occurred among younger participants with strong positive body image perceptions or marriage intentions. 
"I test for HIV whenever a client requests for sex without a condom. I am very pretty and many clients want to have sex with me "live" (without a condom) but I only agree if the man agrees and tests negative (20 year old FSW, Mbale).

\section{Perceived fidelity of test results}

Some participants expressed doubt about the accuracy of their HIV-negative test results. To confirm these results, repeat tests were sought from other clinics. Some FSW reported engaging in unprotected sex, or had HIVpositive clients, but continued to test HIV-negative. Others had doubts about whether a drop of blood drawn from a finger stick could capture their HIV status correctly. When testing was done with a regular client or boyfriend, some FSW sought repeat tests because they feared their client or boyfriend could have bribed clinic staff to change the test result.

"I do not think a drop of blood from a finger gives correct HIV results ... in outreaches, HCW have tested people we know have clients on antiretroviral drugs negative .... I have messed up a lot but they continue test me negative ... I keep testing because I don't believe [my test results]" (32 year old FSW, Kampala).

\section{Habitual testing and self-efficacy}

HIV testing was described as habitual by most participants. Receipt of previous HIV-negative test results gave them courage to test again. Some reported maintaining a diary of testing dates as a reminder.

"I cannot say no to any man who comes with money. I have made it a habit to test for HIV every three months .... I keep a diary where I record dates" (28 year old FSW, Arua).

Prior testing for HIV resulted in empowerment and self-efficacy that was frequently described as a facilitator for engaging in regular HIV testing.

"My parents died of HIV and so my relatives thought I was HIV positive but since I tested negative I have developed the courage to always test for HIV every month" (26 year old FSW, Kampala).

We observed that some participants tested for syphilis because it was offered at an antenatal clinic.

"I have learnt to test for syphilis every three months because when I was pregnant it was a must to be tested for HIV and syphilis" (22 year old FSW, Arua).
Presence of FSW-specific clinics offering both STI and HIV testing

Participants from Kampala, Mbale and Mbarara cited existence of specific FSW-friendly clinics in Kampala as an enabler of their periodic syphilis and HIV testing behaviours. Reasons for preference of these clinics included testing for all STIs, availability of testing kits and medicines, approachable and caring-healthcare providers among others.

"Here in Mbarara I went to government facility but the care was not good ... now days when I go to Kampala I visit a clinic in Mengo because I can explain my problems to doctors ... get counselling and be tested for all STIs ... they care about us and I find it convenient" (28 year old FSW, Mbarara).

NGO clinics that provided integrated services including STI and hepatitis B virus testing at a low cost, promoted syphilis and HIV testing.

"I usually test at RHU, an NGO clinic because even with small money I am tested for syphilis, HIV and hepatitis B" (28 year old FSW, Arua).

\section{Availability of many testing clinics for HIV}

HIV testing services were reported to be easily accessible in all cities. All participants cited existence of several testing facilities ranging from free government clinics, NGO clinics, private clinics, and occasionally community-based testing outreaches.

"For me, it is easy to test for HIV every 3 months because there are many testing centers. I used to test from the main hospital but when healthcare workers know your business (sex work) they take long to serve you ... .now I go the health center" (29 year old FSW, Arua).

These facilities provided choice regarding availability, acceptability, convenience, and affordability. The commonly preferred testing sites were FSW-friendly clinics, public health facilities, and NGO run clinics. Private clinics and community-based outreach campaigns were the least preferred.

I used to test from a private clinic but I worried a lot waiting for results ... at the main hospital, services are free and healthcare workers prepare you before (pre-test counselling) and after testing ... .you get a lot of information about HIV" (28 year old FSW, Mbale).

Reasons for these preferences included provision of a range of STI testing services, availability of testing kits 
and antibiotics, approachable and kind HCW for specific FSW-clinics. Public health clinics offered free testing services, health education and pre-test counselling. Private clinics were preferred for being nearby or trusted to provide accurate test results. Outreach campaigns were said to be convenient.

"I do sometimes test for HIV and syphilis at the MARPI clinic at Mulago especially when I want to get PEP ... .but normally I test from private clinics because they are near or when healthcare workers come and test us from here" (30 year old FSW, Kampala).

\section{Discussion}

Understanding and addressing barriers and facilitators of syphilis and HIV testing among FSW in Uganda is crucial to increasing prevention coverage and decreasing HIV and syphilis burden in this population. Across both individual and health system barriers, our results suggest that much work remains to optimize HIV/STI testing for FSW. This paper shows that FSW face substantial barriers accessing HIV/STI testing because of (1) disrespectful, judgmental, and unfriendly provider attitudes; (2) interpersonal and internalized stigma; (3) unfavorable clinic operating hours; (4) non-emphasis of syphilis testing because of policy recommendations for syndromic STI management; and (5) frequent stock outs of syphilis test kits, high cost of syphilis tests, and low perceived severity of syphilis infection. Given the importance of increasing FSW engagement in HIV/STI care, this study identifies crucial areas that should be addressed at health system and individual level to improve the providerpatient relationship, empower FSW to overcome these barriers to care, and increase utilization of testing services.

Our study shows that stigma was experienced at individual and interpersonal levels. Internalized stigma (negative beliefs someone holds about themselves and their identity) and interpersonal stigma (direct or enacted forms of stigma including judgmental attitudes and having sex workers wait longer for care) are well described barriers to testing uptake because of criminalization of sex work and negative social norms $[11,18,19,40]$. Internalized stigma was heightened by fears of disclosure of positive HIV or syphilis test results within sex worker peer networks. Reports of discrimination at public health facilities were attributed to interpersonal stigma. FSW commonly experience stigma in health service delivery [41], and negative experiences with $\mathrm{HCW}$ are associated with delay or avoidance of testing which is a critical entry point to HIV/STI care [42, 43]. Qualitative work from Kenya and Zimbabwe echoes our finding that stigma from $\mathrm{HCW}$ influences health seeking behaviors [43, 44]. Stigma-reduction interventions should include key population sensitivity training for providers, which has been shown to decrease judgemental and discriminatory attitudes among $\mathrm{HCW}$ in sub-Saharan Africa [45].

Participants felt it was easier to request for an HIV test at health facilities in contrast to syphilis where such a request attracted embarrassing and critical questioning from providers. This was attributed to the availability of several HIV testing facilities and the normative nature of HIV testing. FSW focused clinics were mainly located in Kampala, whereas public, private, and NGO clinics or community-based outreaches were reported to offer HIV testing in other cities as previously reported [11]. The diversity of HIV testing facilities provided choice about service availability, responsiveness, convenience, and affordability which helped FSW circumvent health system barriers. FSW utilization of health services was also limited by unfavorable clinic operating hours, unavailability of test kits, and high cost, factors previously reported as structural barriers to HIV testing uptake $[11,17,20]$. Specialized FSW and NGO clinics were preferred because they offered integrated STI and HIV services, shorter waiting times, availability of treatment, friendly and caring HCW. Similar findings have been reported from India, Mozambique, Kenya and South Africa [20,46]. However, most of these studies focused on HIV testing.

Our finding that regular testing was motivated by fears and concerns over maintaining health, ability to work, family responsibilities, and future aspirations or social influences, and was facilitated by testing habits and selfefficacy is consistent with prior work in which perceived benefits of testing or attitudes, self-efficacy, social influences and past behavior have been reported to influence STI testing [16, 47-49]. STI risk perception was high, but disease severity was perceived differently. HIV was perceived a serious health threat and testing meant getting psychological respite or access to treatment to extend one's life or prevent HIV, work to provide for self and significant others. In contrast, syphilis was perceived a less serious threat and the misconception that one needed to develop symptoms before testing was widespread as previously reported [50]. Syphilis testing was facilitated by dual syphilis/HIV testing which is standard-of-care during pregnancy in Uganda [51], and was motivated by concerns over satisfaction of customers, HIV acquisition risk, and infertility. The belief that syphilis increased risk of HIV acquisition or reduced capacity to satisfy customers was common among older participants. Younger participants with childbearing and marriage intentions believed syphilis caused infertility. Some of these beliefs and misconceptions show lack of 
comprehensive knowledge about syphilis. Despite the paucity of data on drivers of syphilis testing among FSW, our findings support evidence showing that knowledge of testing benefits and attitudes influences STI testing behaviors $[16,17,52]$. At individual level, fear of being seen at the clinic was a barrier to dual syphilis and HIV testing.

Social influences (i.e., influence of referent others) [53] motivated testing among participants with distant regular partners. Male partners were usually unaware of female engagement in sex work and HIV testing occurred whenever they met or in anticipation of meeting because the partner demanded pre-sex testing for fear of being infected. Fear of infecting a male client has been reported to motivate HIV testing among FSW in Russia [52]. However, in our study fear of being infected by male partners and clients following payment of larger sums of money for unprotected sex motivated periodic HIV testing among FSW with high self-efficacy. Empowerment interventions including skills training that have been found to build the self-efficacy and promote HIV testing among FSW [18] should be strengthened, and tailored to the specific needs of FSW. Surprisingly, doubts over the accuracy of HIV-negative test results was reported as a motivation for periodic testing despite also being documented as a barrier [11]. This was mainly due to beliefs that a FSW cannot test HIV-negative because of sexual risk behaviors or that a drop of blood from finger stick cannot give correct test results. Such sentiments indicate lack of comprehensive knowledge about HIV that should be strengthened in HIV educational campaigns to FSW. The desire to confirm test results, get psychological satisfaction or access treatment prompted testing frequently at various health facilities.

Public facilities were reported to have limited focus on syphilis serological screening despite offering HIV pretesting counselling, health education, and free services. In this setting, public health programs emphasize HIV testing for FSW [11-13, 54] perhaps because of funding priorities or testing guidelines. Additionally, syndromic STI management is standard-of-care in this setting. This may explain why providers rarely encouraged syphilis testing. Our findings suggest programs should also emphasize periodic testing for syphilis and other STIs. Uganda guidelines now recommend dual syphilis and HIV for pregnant women and their partners [51]. Dual testing was introduced to achieve elimination of motherto-child transmission of HIV and syphilis. Extending such services to FSW could change attitudes of health providers, including messaging on routine syphilis testing, and improve testing uptake for the two infections. Higher uptake of syphilis screening services among FSW is a key pillar of the 2040 global efforts to end the STI epidemic $[5,55]$.
The clinical and policy implications of our findings include assessing fears and concerns about regular syphilis and HIV testing at service delivery points, tailoring health promotion messages to addressing these fears and concerns, developing messages emphasizing routine syphilis and HIV testing in HIV and ANC clinics for FSW, developing and strengthening stigma-reduction interventions for FSW and health providers, and extending the dual syphilis and HIV testing approach to FSW.

The strengths of our study include a qualitative exploration of barriers and facilitators of dual syphilis and HIV testing among a geographically diverse sample of FSW in Uganda. Our findings contribute to the evidence base of HIV and STI testing in a setting where several studies focus only on HIV. The limitations of this explorative qualitative study include purposeful sampling of FSW who reported engaging in regular syphilis and HIV testing behaviors. Hence our findings may largely reflect FSW who are knowledgeable about benefits of regular testing and have self-efficacy despite encountering barriers to testing. We only used in-depth interviews to collect data. However, focus groups are not a good choice for in-depth study of sensitive topics and limit interaction with individual participants. Additionally, we did not explore the influence of brothel owners and pimps on testing behaviors of FSW. Nevertheless, similar findings have been reported in studies employing indepth interviews, focus group discussions, and key informant interviews.

\section{Conclusions}

This study shows that despite the existence of multilevel barriers, regular HIV testing among FSW is facilitated by availability of testing facilities and welcoming healthcare environments. Availability of syphilis serological testing services was very limited. Interventions to improve uptake of syphilis and HIV testing among FSW in Uganda need multilevel frameworks targeting both FSW and providers and policy makers. Community empowerment programs that address knowledge gaps and misconceptions should emphasize periodic testing for both syphilis and HIV. To increase availability of testing services, there is need to recommend dual syphilis and HIV testing for FSW in national guidelines, provide sensitization training for $\mathrm{HCW}$ and deliver services while respecting human rights of FSW.

\section{Abbreviations \\ FSW: female sex workers; HIV: human immunodeficiency virus; STI: sexually transmitted infection; WHO: World Health Organization}

\section{Acknowledgements}

Richard Muhindo is a NURTURE fellow funded through grant D43TW010132 from the National Institutes of Health. Special thanks to NURTURE program, mentors and the secretariat. He is also a PhD scholar under the Johnson \& Johnson Corporate Citizenship Trust grant at Ugandan Academy of Health 
Innovation and Impact, Infectious Diseases Institute Uganda. Special thanks to the Infectious Diseases Institute (IDI), PhD scholar Mentorship program, the IDI and Makerere University School of Public Health PhD scholar forums. Special mention goes to Moses Mukuru, Dr. Green Wendy and Dr. Soson Jong who separately prepared and reviewed the codes. The authors thank the leadership of the cities of Mbarara, and Mbale which enabled the data collection process. We thank the participants for volunteering to participate in the study. Finally, we thank Collins Twesigye, and Jonan Mweteise who worked as research assistants.

\section{Authors' contributions}

RM conceived the research idea, participated in the design of the study including data collection, and drafting of the manuscript. BC, RP, NKS, JK, NMT, AM, and EN, all participated in refining the idea and design of interview guide. RM, JK, BC and AM, participated in data analysis. RM, AM and $B C$, wrote the first draft. All authors contributed to the interpretation of the study results, review of the manuscript, and all approved the final manuscript.

\section{Funding}

This study was supported through grant number D43TW010132 supported by Office of The Director, National Institutes Of Health (OD), National Institute Of Dental \& Craniofacial Research (NIDCR), National Institute Of Neurological Disorders And Stroke (NINDS), National Heart, Lung, And Blood Institute (NHLBI), Fogarty International Center (FIC), National Institute On Minority Health And Health Disparities (NIMHD) and a grant from the Ugandan Academy of Health Innovation and Impact. The Ugandan Academy is initially funded by Janssen, the Pharmaceutical Companies of Johnson \& Johnson as part of its commitment to global public health through collaboration with the Johnson \& Johnson Corporate Citizenship Trust. AM was supported through grant K43TW010695 from the US National Institutes of Health.

\section{Availability of data and materials}

The datasets used during the current study are available from the corresponding author on request. The questionnaire is included as supplementary information.

\section{Declarations}

\section{Ethics approval and consent to participate}

All methods were carried out in accordance with ethical guidelines and regulations in Uganda. Ethical clearance for the study was obtained from the Higher Degrees, Research and Ethics Committee, School of Public Health, Makerere University and Uganda National Council for Science and Technology (HS 2403). All respondents provided written informed consent in English or their local language. Non-educated respondents signed consent forms using their thumb impressions, a procedure that was approved by the Higher Degrees, Research and Ethics Committee, School of Public Health Makerere University.

\section{Consent for publication}

Not applicable.

\section{Competing interests}

The author(s) declare that they have no competing interests.

\section{Author details}

${ }^{1}$ Department of Nursing, College of Health Sciences, Makerere University, Kampala, Uganda. ${ }^{2}$ Infectious Diseases Institute, College of Health Sciences, Makerere University, Kampala, Uganda. ${ }^{3}$ School of Public Health, College of Health Sciences, Makerere University, Kampala, Uganda. ${ }^{4}$ School of Medicine, College of Health Sciences, Makerere University, Kampala, Uganda. ${ }^{5}$ Cambridge Institute of Public Health, University of Cambridge, Cambridge, UK.

Received: 11 August 2021 Accepted: 22 October 2021 Published online: 02 November 2021

\section{References}

1. WHO: Report on global sexually transmitted infection surveillance 2018. 2018.
2. Sharma M, Rewari BB, Aditama TY, Turlapati P, Dallabetta G, Steen R. Control of sexually transmitted infections and global elimination targets, South-East Asia region. Bull World Health Organ. 2021;99(4):304-11. https://doi.org/1 0.2471/BLT.20.254003.

3. Seale A, Broutet N, Narasimhan M. Assessing process, content, and politics in developing the global health sector strategy on sexually transmitted infections 2016-2021: implementation opportunities for policymakers. PLoS Med. 2017;14(6):e1002330. https://doi.org/10.1371/journal.pmed.1002330.

4. Global AIDS. Update. Seizing the moment, tackling entrenched inequalities to end epidemics. Published online; 2020. p. 384.

5. WHO: Global health sector strategy on sexually transmitted infections 2016 2021: toward ending STIs. 2016.

6. WHO: Report on global sexually transmitted infection surveillance. 2018

7. UNAIDS: Understanding Fast-Track: Accelerating Action to end the AIDS Epidemic by 2030. 2014

8. UNAIDS. Global AIDS Update 2020: Seizing the moment, tackling entrenched inequalities to end epidemics. https://www.unaids.org/sites/default/files/ media_asset/2020_global-aids-report_en.pdf. Accessed 27 Sept 2021.

9. Prevention and treatment of HIV and other Sexually Transmitted Infections for Sex Workers in Low and Middle-Income Countries: Recommendations for a public health approach [https://apps.who.int/iris/bitstream/handle/1 0665/77745/9789241504744_eng.pdf?sequence=1].

10. Delivering HIV Test Results and Messages for Re-Testing and Counselling in Adults. Geneva, Switzerland: WHO Library Cataloguing-in-publication Data; 2010. [https://apps.who.int/iris/bitstream/handle/10665/44278/9789241 599115_eng.pdf?sequence=1].

11. Wanyenze RK, Musinguzi G, Kiguli J, Nuwaha F, Mujisha G, Musinguzi J, et al. "When they know that you are a sex worker, you will be the last person to be treated": perceptions and experiences of female sex workers in accessing HIV services in Uganda. BMC Int Health Hum Rights. 2017;17(1):11. https:// doi.org/10.1186/s12914-017-0119-1.

12. $\mathrm{MOH}$ : National HIV Testing Services Policy and Implementation Guidelines Uganda. 2016.

13. Uganda AIDS Commission: National HIV and AIDS Priority Action Plan 2018/ 2019-2019/2020. 2018.

14. Muldoon KA. A systematic review of the clinical and social epidemiological research among sex workers in Uganda. BMC Public Health. 2015;15(1):1226. https://doi.org/10.1186/s12889-015-2553-0.

15. Hladik W, Baughman AL, Serwadda D, Tappero JW, Kwezi R, Nakato ND, et al. Burden and characteristics of HIV infection among female sex workers in Kampala, Uganda-a respondent-driven sampling survey. BMC Public Health. 2017;17(1):565. https://doi.org/10.1186/s12889-017-4428-z.

16. Muhindo R, Castelnuovo B, Mujugira A, Parkes-Ratanshi R, Sewankambo NK, Kiguli J, et al. Psychosocial correlates of regular syphilis and HIV screening practices among female sex workers in Uganda: a cross-sectional survey. AIDS Res Ther. 2019;16(1):28. https://doi.org/10.1186/s12981-019-0244-0.

17. Nnko S, Kuringe E, Nyato D, Drake M, Casalini C, Shao A, et al. Determinants of access to HIV testing and counselling services among female sex workers in sub-Saharan Africa: a systematic review. BMC Public Health. 2019;19(1):15. https://doi.org/10.1186/s12889-018-6362-0.

18. Shannon K, Strathdee SA, Goldenberg SM, Duff P, Mwangi P, Rusakova M, et al. Global epidemiology of HIV among female sex workers: influence of structural determinants. Lancet. 2015;385(9962):55-71. https://doi.org/10.101 6/S0140-6736(14)60931-4.

19. Chanda MM, Perez-Brumer AG, Ortblad KF, Mwale M, Chongo S, Kamungoma N, et al. Barriers and facilitators to HIV testing among Zambian female sex workers in three transit hubs. AIDS Patient Care STDS. 2017;31(7): 290-6. https://doi.org/10.1089/apc.2017.0016.

20. Lafort Y, Greener R, Roy A, Greener L, Ombidi W, Lessitala F, et al. Where do female sex workers seek HIV and reproductive health care and what motivates these choices? A survey in 4 cities in India, Kenya, Mozambique and South Africa. Plos One. 2016;11(8):e0160730. https://doi.org/10.1371/ journal.pone.0160730.

21. Tokar A, Broerse JE, Blanchard J, Roura M. HIV testing and counseling among female sex workers: a systematic literature review. AIDS Behav. 2018; 22(8):2435-57. https://doi.org/10.1007/s10461-018-2043-3.

22. Woodford MR, Chakrapani V, Newman PA, Shunmugam M. Barriers and facilitators to voluntary HIV testing uptake among communities at high risk of HIV exposure in Chennai, India. Glob Public Health. 2016;11(3):363-79. https://doi.org/10.1080/17441692.2015.1057757. 
23. Mitchell KM, Cox AP, Mabey D, Tucker JD, Peeling RW, Vickerman P. The impact of syphilis screening among female sex workers in China: a modelling study. PLoS One. 2013;8(1):e55622. https://doi.org/10.1371/journa l.pone.0055622.

24. Ouedraogo HG, Meda IB, Zongo I, Ky-Zerbo O, Grosso A, Samadoulougou $B C$, et al. Syphilis among female sex workers: results of point-of-care screening during a cross-sectional behavioral survey in Burkina Faso, West Africa. Int J Microbiol. 2018;2018:1-10. https://doi.org/10.1155/2018/4790560.

25. Black V, Williams BG, Maseko V, Radebe F, Rees HV, Lewis DA. Field evaluation of standard Diagnostics' bioline HIV/syphilis duo test among female sex workers in Johannesburg, South Africa. Sex Transm Infect. 2016; 92(7):495-8. https://doi.org/10.1136/sextrans-2015-052474.

26. Muhindo R, Mujugira A, Castelnuovo B, Sewankambo NK, Parkes-Ratanshi R, Kiguli J, et al. Text message reminders and peer education increase HIV and syphilis testing among female sex workers: a pilot quasi-experimental study in Uganda. BMC Health Serv Res. 2021;21(1):1-11. https://doi.org/10.1186/ s12913-021-06461-w.

27. Uganda Bureau of Statistics. Enhancing Data Quality and Use. (Uganda: Uganda Bureau of Statistics Kampala; 2019.

28. Mulholland GE, Markiewicz M, Arimi P, Ssengooba F, Weir S, Edwards JK. HIV prevalence and the HIV treatment Cascade among female sex Workers in Cross-Border Areas in East Africa. AIDS Behav. 2021:1-13. https://doi.org/10.1 007/s10461-021-03411-9.

29. Ouma J, Jeffery C, Awor CA, Muruta A, Musinguzi J, Wanyenze RK, et al. Model-based small area estimation methods and precise district-level HIV prevalence estimates in Uganda. PLoS One. 2021;16(8):e0253375. https://doi. org/10.1371/journal.pone.0253375.

30. Creswell JW, Hanson WE, Clark Plano VL, Morales A. Qualitative research designs: selection and implementation. Couns Psychol. 2007;35(2):236-64. https://doi.org/10.1177/0011000006287390.

31. Sargeant J: Qualitative research part II: Participants, analysis, and quality assurance. In.: The Accreditation Council for Graduate Medical Education Suite $2000,515 \ldots ; 2012$.

32. Terry G, Hayfield N, Clarke V, Braun V. Thematic analysis. The Sage handbook of qualitative research in psychology; 2017. p. 17-37. https://doi.org/10.413 5/9781526405555.n2

33. Bengtsson M. How to plan and perform a qualitative study using content analysis. Nursing Plus Open. 2016;2:8-14. https://doi.org/10.1016/..npls.2016. 01.001.

34. Braun V, Clarke V: Using thematic analysis in psykology. Qualitative Research in Psykology 3 (2): 77 2006, 101.

35. Creswell JW, Creswell JD. Research design: qualitative, quantitative, and mixed methods approaches: sage publications; 2017.

36. Graneheim UH, Lundman B. Qualitative content analysis in nursing research: concepts, procedures and measures to achieve trustworthiness. Nurse Educ Today. 2004;24(2):105-12. https://doi.org/10.1016/j.nedt.2003.10.001.

37. Maxwell AE. Analysing qualitative data. London: Methuen; 1961.

38. Seers K. Qualitative data analysis. Evid Based Nurs. 2012;15(1):2-2. https:// doi.org/10.1136/ebnurs.2011.100352.

39. Tong A, Sainsbury P, Craig J. Consolidated criteria for reporting qualitative research (COREQ): a 32-item checklist for interviews and focus groups. International J Qual Health Care. 2007;19(6):349-57. https://doi.org/10.1093/ intqhc/mzm042.

40. Baral S, Beyrer C, Muessig K, Poteat T, Wirtz AL, Decker MR, et al. Burden of HIV among female sex workers in low-income and middle-income countries: a systematic review and meta-analysis. Lancet Infect Dis. 2012; 12(7):538-49. https://doi.org/10.1016/S1473-3099(12)70066-X.

41. Scorgie F, Nakato D, Harper E, Richter M, Maseko S, Nare P, et al. 'We are despised in the hospitals': sex workers' experiences of accessing health care in four African countries. Cult Health Sex. 2013;15(4):450-65. https://doi. org/10.1080/13691058.2012.763187.

42. Mountain E, Pickles M, Mishra S, Vickerman P, Alary M, Boily M-C. The HIV care cascade and antiretroviral therapy in female sex workers: implications for HIV prevention. Expert Rev Anti Infect Ther. 2014;12(10):1203-19. https:// doi.org/10.1586/14787210.2014.948422.

43. Nyblade L, Reddy A, Mbote D, Kraemer J, Stockton M, Kemunto C, et al. The relationship between health worker stigma and uptake of HIV counseling and testing and utilization of non-HIV health services: the experience of male and female sex workers in Kenya. AIDS Care. 2017;29(11):1364-72. https://doi.org/10.1080/09540121.2017.1307922.
44. Mtetwa S, Busza J, Chidiya S, Mungofa S, Cowan F. "You are wasting our drugs": health service barriers to HIV treatment for sex workers in Zimbabwe. BMC Public Health. 2013;13(1):1-7. https://doi.org/10.1186/14 71-2458-13-698.

45. Fong-Jaen F, Duby Z, Nkosi B, Brown B, Scheibe A. 'We must treat them like all the other people': evaluating the integrated key populations sensitivity training programme for healthcare workers in South Africa. South African J HIV Medicine. 2019;20(1):1-7. https://doi.org/10.4102/sajhivmed.v20i1.909.

46. Pande G, Bulage L, Kabwama S, Nsubuga F, Kyambadde P, Mugerwa S, et al. Preference and uptake of different community-based HIV testing service delivery models among female sex workers along Malaba-Kampala highway, Uganda, 2017. BMC Health Serv Res. 2019;19(1):799. https://doi. org/10.1186/s12913-019-4610-3.

47. De Vries H. An integrated approach for understanding health behavior; the I-change model as an example. Psychol Behav Sci Int J. 2017;2(2):10.19080. https://doi.org/10.19080/PBSIJ.2017.02.555585.

48. Wong WC-W, Yuen WW-Y, Tang CS-K, Holroyd E, Fong DY-T. Evaluation and mechanism analysis of HIV prevention programme using resilience framework among female sex workers: a randomised controlled trial. Prev Med Rep. 2019;13:229-37. https://doi.org/10.1016/j.pmedr.2018.12.007.

49. Oldenburg CE, Ortblad KF, Chanda MM, Mwanda K, Nicodemus W, Sikaundi $R$, et al. Zambian peer educators for HIV self-testing (ZEST) study: rationale and design of a cluster randomised trial of HIV self-testing among female sex workers in Zambia. BMJ Open. 2017;7(4)::014780. https://doi.org/10.113 6/bmjopen-2016-014780

50. Nakku-Joloba E, Kiguli J, Kayemba CN, Twimukye A, Mbazira JK, ParkesRatanshi $R$, et al. Perspectives on male partner notification and treatment for syphilis among antenatal women and their partners in Kampala and Wakiso districts, Uganda. BMC Infect Dis. 2019;19(1):124. https://doi.org/1 0.1186/s12879-019-3695-y.

51. Republic of Uganda: Consolidated Guidelines for the Prevention and Treatment of HIV and AIDS in Uganda In. Edited by Health Mo; 2020.

52. King EJ, Maman S, Dudina VI, Moracco KE, Bowling JM. Motivators and barriers to HIV testing among street-based female sex workers in St. Petersburg, Russia. Glob Public Health. 2017;12(7):876-91. https://doi.org/1 0.1080/17441692.2015.1124905.

53. de Vries H, Mesters I, Van de Steeg H, Honing C. The general public's information needs and perceptions regarding hereditary cancer: an application of the integrated change model. Patient Educ Couns. 2005;56(2): 154-65. https://doi.org/10.1016/j.pec.2004.01.002.

54. Batona G, Gagnon M-P, Simonyan DA, Guedou FA, Alary M. Understanding the intention to undergo regular HIV testing among female sex workers in Benin: a key issue for entry into HIV care. J Acquir Immune Defic Syndr. 2015;68(Supplement 2):S206-12. https://doi.org/10.1097/QAl. 0000000000000452.

55. WHO. Sexually transmitted infections: implementing the global STI strategy. http://apps.who.int/iris/bitstream/handle/10665/258740/WHO-RHR-17.18eng.pdf;jsessionid=56485F2F5BD66171A62AF8F971663FDB? sequence=1. Accessed 27 May 2021.

\section{Publisher's Note}

Springer Nature remains neutral with regard to jurisdictional claims in published maps and institutional affiliations.

Ready to submit your research? Choose BMC and benefit from:

- fast, convenient online submission

- thorough peer review by experienced researchers in your field

- rapid publication on acceptance

- support for research data, including large and complex data types

- gold Open Access which fosters wider collaboration and increased citations

- maximum visibility for your research: over $100 \mathrm{M}$ website views per year

At $\mathrm{BMC}$, research is always in progress.

Learn more biomedcentral.com/submission 